\title{
Towards a barnacle tree of life: Integrating diverse phylogenetic efforts into a comprehensive hypothesis of thecostracan evolution
}

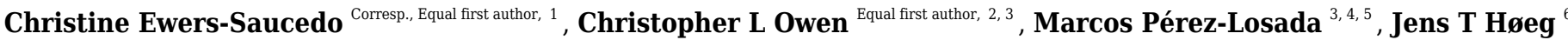 \\ , Henrik Glenner ${ }^{7}$, Benny KK Chan ${ }^{8}$, Keith A Crandall ${ }^{3,4}$ \\ ${ }^{1}$ Zoological Museum, Christian-Albrechts University, Kiel, Germany \\ 2 Systematic Entomology Laboratory, USDA-ARS, Beltsville, MD, Unites States of America \\ ${ }^{3}$ Computational Biology Institute, Milken Institute School of Public Health, George Washington University, Ashburn, VA, Unites States of America \\ 4 Department of Invertebrate Zoology, US National Museum of Natural History, Smithsonian Institution, Washington, DC, Unites States of America \\ 5 CIBIO-InBIO, Centro de Investigação em Biodiversidade e Recursos Genéticos, Universidade do Porto, Vairão, Portugal \\ 6 Marine Biology Section, Department of Biology, University of Copenhagen, Copenhagen, Denmark \\ 7 Marine Biodiversity Group, Department of Biology, University of Bergen, Bergen, Norway \\ 8 Biodiversity Research Center, Academia Sinica, Taipei, Taiwan \\ Corresponding Author: Christine Ewers-Saucedo \\ Email address: ewers-saucedo@zoolmuseum.uni-kiel.de
}

Barnacles and their allies (Thecostraca) are a biologically diverse, monophyletic crustacean group, which includes both intensely studied taxa, such as the acorn and stalked barnacles, as well as cryptic taxa, e.g., Facetotecta. Recent efforts have clarified phylogenetic relationships in many different parts of the barnacle tree, but the outcomes of these phylogenetic studies have not yet been combined into a single hypothesis for all barnacles. In the present study, we applied a new 'synthesis' tree approach to estimate the first working Barnacle Tree of Life. Using this approach, we integrated phylogenetic hypotheses from 27 studies, which did not necessarily include the same taxa or used the same characters, with hierarchical taxonomic information for all recognized species. This first synthesis tree contains 2,070 barnacle species and subspecies, including 239 barnacle species with phylogenetic information and 198 undescribed or unidentified species. The tree had 442 bifurcating nodes, indicating that $79.3 \%$ of all nodes are still unresolved. We found that the acorn and stalked barnacles, the Thoracica, and the parasitic Rhizocephala have the largest amount of published phylogenetic information. About half of the thecostracan families for which phylogenetic information was available were polyphyletic. We queried publicly available geographic occurrence databases for the group, gaining a sense of geographic gaps and hotspots in our phylogenetic knowledge. Phylogenetic information is especially lacking for deep sea and Arctic taxa, but even coastal species are not fully incorporated into phylogenetic studies. 
2 Towards a barnacle tree of life: Integrating diverse 3 phylogenetic efforts into a comprehensive hypothesis 4 of thecostracan evolution

5

6
Christine Ewers-Saucedo ${ }^{1}$, Christopher L. Owen ${ }^{2,3}$, Marcos Pérez-Losada ${ }^{3,4,5}$, Jens T. Høeg 6 , Henrik Glenner ${ }^{7}$, Benny K. K. Chan ${ }^{8}$ \& Keith A. Crandall ${ }^{3,4}$

${ }^{1}$ Zoological Museum, Christian-Albrechts University, 24105 Kiel, Germany

${ }^{2}$ Systematic Entomology Laboratory, USDA-ARS, BARC-West, Beltsville, MD 20705, United

States of America

${ }^{3}$ Computational Biology Institute, Milken Institute School of Public Health, George Washington University, Ashburn, VA, United States of America

${ }^{4}$ Department of Invertebrate Zoology, US National Museum of Natural History, Smithsonian Institution, Washington, DC, 20013, USA

${ }^{5}$ CIBIO-InBIO, Centro de Investigação em Biodiversidade e Recursos Genéticos, Universidade do Porto, Portugal

${ }^{6}$ Marine Biology Section, Department of Biology, University of Copenhagen, Copenhagen, Denmark

${ }^{7}$ Marine Biodiversity Group, Department of Biology, University of Bergen, Bergen, Norway

${ }^{8}$ Biodiversity Research Center, Academia Sinica, Taipei, Taiwan

Corresponding Author:

Christine Ewers-Saucedo ${ }^{1}$

Hegewischstrasse 3, 24105 Kiel, Germany

Email address: ewers-saucedo@,zoolmuseum.uni-kiel.com 


\section{Abstract}

Barnacles and their allies (Thecostraca) are a biologically diverse, monophyletic crustacean group, which includes both intensely studied taxa, such as the acorn and stalked barnacles, as well as cryptic taxa, e.g., Facetotecta. Recent efforts have clarified phylogenetic relationships in many different parts of the barnacle tree, but the outcomes of these phylogenetic studies have not yet been combined into a single hypothesis for all barnacles. In the present study, we applied a new 'synthesis' tree approach to estimate the first working Barnacle Tree of Life. Using this approach, we integrated phylogenetic hypotheses from 27 studies, which did not necessarily include the same taxa or used the same characters, with hierarchical taxonomic information for all recognized species. This first synthesis tree contains 2,070 barnacle species and subspecies, including 239 barnacle species with phylogenetic information and 198 undescribed or unidentified species. The tree had 442 bifurcating nodes, indicating that $79.3 \%$ of all nodes are still unresolved. We found that the acorn and stalked barnacles, the Thoracica, and the parasitic Rhizocephala have the largest amount of published phylogenetic information. About half of the thecostracan families for which phylogenetic information was available were polyphyletic. We queried publicly available geographic occurrence databases for the group, gaining a sense of geographic gaps and hotspots in our phylogenetic knowledge. Phylogenetic information is especially lacking for deep sea and Arctic taxa, but even coastal species are not fully incorporated into phylogenetic studies.

\section{Introduction}

The Thecostraca, which include not only the barnacles (Cirripedia), but also the Facetotecta, Ascothoracida, and possibly the Tantulocarida (Petrunina et al., 2013), is a highly variable crustacean group in terms of both morphology and biology (Ruppert et al., 2003; Høeg and Møller, 2006) (Fig. 1). This makes them prime models for studying evolutionary adaptations in diverse fields including morphology, ontogeny, and reproductive systems (Charnov, 1987; Høeg et al., 2009; Yusa et al., 2012; Lin et al., 2015). In fact, the specializations in adult morphology, growth, feeding biology and sexual systems prompted Darwin to study barnacles, resulting in one of the first "model organisms" of evolutionary adaptation (Darwin 1851a; Darwin 1851b; Darwin 1854; Darwin 1855). Recent work has assessed phylogenetic relationships among the barnacles at both the higher (Buckeridge, 1995; Korn, 1995; Harris et al., 2000; Pérez-Losada et al., 2002; Pérez-Losada et al., 2004; Glenner and Hebsgaard, 2006; Mallatt and Giribet, 2006; Pérez-Losada et al., 2008; Høeg et al., 2009) and lower (e.g., Mokady et al., 1999; SimonBlecher et al., 2007; Shemesh et al., 2009; Brickner et al., 2010; Pérez-Losada et al., 2014; Lin et al., 2015; Gale, 2018 in press, Lin et al., 2016) taxonomic ranks. These studies have provided great insight into barnacle evolution, confirming morphological patterns in some cases, and highlighting substantial convergence in others. For example, genetic data revealed a case of deep convergence in the metamorphosing stages of Rhizocephala and Facetotecta (Perez-Losada et al., 2009), with morphologically very similar slug-shaped stages. In another case, the basal position of Ibliformes within the acorn and stalked barnacles (Thoracica) was confirmed both by the presence of several plesiomorph shell characters and molecular phylogenetics (Hoeg et al., 2009; Perez-Losada et al., 2008). Within the monophyletic Thoracica, the Sessilia (acorn barnacles) are nested within the Pedunculata (stalked barnacles), and the stalk has been lost more than once (e.g. Neoverrucca), rendering Pedunculata polyphyletic (Perez-Losada et al., 2008). Genetic studies confirmed the morphologically suggested sister relationship between Balanomorpha and 
85 Verruccomorpha (Perez-Losada et al. 2008). The often-hypothesized gradual increase of shell

86 plate numbers during the evolution of Thoracica, on the other hand, could not be confirmed

87 (Perez-Losada et al., 2008). As a consequence of the diverse phylogenetic efforts, few studies

88 have included enough of the same taxa or used the same characters to allow an estimate of the

89 Barnacle Tree of Life up to now.

90 The inability to combine studies into a single phylogenetic tree for all barnacles is

91 primarily because studies did not include the same species, which is required by supertree

92 methodology, or did not use the same characters (genes or morphology), which is required by

93 supermatrix approaches. Supertree approaches code phylogenies and their represented

94 relationships in a new matrix to be analysed by phylogenetic methods, and they typically require

95 that a significant number of the same taxa are present in each study to effectively integrate

96 multiple phylogenies into a single tree (for a review see Binida-Emonds, 2004). Supermatrix

97 approaches, on the other hand, require the same character sets (e.g., nucleotides, proteins,

98 morphological characters, etc.) to be used by each study, and usually contain large amounts of

99 missing data (e.g., Driscell et al., 2004; Ciccarelli et al., 2006; McMahon and Sanderson, 2006).

100 This is especially problematic with morphological characters as very different characters have

101 been used at the higher taxonomic ranks compared to lower ranks, and in some groups (e.g.,

102 parasitic barnacles) it is impossible to determine character homology. Within Thecostraca, larval

103 characters are the only ones that can be compared across all taxa, but compiling and coding such

104 information is cumbersome and time consuming, especially for rare and hard to sample species

105 (e.g. Yorisue et al., 2016). Similarly, genetic data sets are also hard to combine since experts tend

106 to use different (sometimes completely different) sets of genetic markers. Given the relative lack

107 of matching data across barnacle studies, we have decided to apply a new 'synthesis' tree

108 approach (Hinchliff et al., 2015) in an attempt to estimate the first working Barnacle Tree of

109 Life. The synthesis tree approach (Hinchliff et al., 2015; Redelings and Holder, 2017) maps

110 phylogenetic hypotheses onto underlying hierarchical taxonomic information (Rees and

111 Cranston, 2017). This results in an integration of both phylogenetic and taxonomic information

112 onto a single phylogenetic tree that combines phylogenetic relatedness and taxonomic

113 knowledge. This approach also readily highlights those areas of the taxonomy that lack

114 previously published phylogenetic information. Because the phylogenetic information is

115 incorporated as is (i.e., there is no 'supermatrix' construction and no re-estimation), any

116 phylogenetic hypothesis can be incorporated regardless of its data basis, hence morphological

117 and/or molecular trees can be integrated without a need for congruent character sets or gene

118 regions.

119 Given the recent and diverse phylogenetic and genomic efforts across the barnacles, we

120 felt that now was a particularly opportune time to summarize the barnacle phylogeny efforts

121 using phylogenetic synthesis. Indeed, reasonably detailed molecular based trees are now

122 available for most of the major thecostracan groups (Rhizocephala: Glenner and Hebsgaard,

123 2006; Glenner et al., 2010; Thoracica: Pérez-Losada et al., 2008; 2014; Lin et al., 2015; Chan et

124 al., 2017 Acrothoracica: Lin et al., 2016), and several studies have dealt with lower taxonomic

125 ranks (e.g., coral barnacles: Mokady et al., 1999; Simon-Blecher etal., 2007; Brickner et al.,

126 2010; Chen, 2012; Tsang et al., 2014; Simon-Blecher et al., 2016). Our goal is to summarize all

127 previously published barnacle phylogenies to highlight areas for future systematic research effort

128 by quickly identifying areas of the taxonomy that lack phylogenetic information as well as areas

129 where there are 1) conflicting phylogenetic hypotheses and/or 2) conflicting phylogenetic and

130 taxonomic information (i.e., non-monophyletic taxa). Additionally, a synthesis tree can also 
131 couple taxonomic/systematic information with geographic information and taxa distributions and

132

133

134

135

136

137

138

139

140

141

142

143

144

145

146

147

148

149

150

151

152

153

154

155

156

157

158

159

160

161

162

163

164

165

166

167

168

169

170

171

172

173

174

175

176

thereby quickly pinpoint geographic areas for future collecting efforts to add genetic or morphological data to the leaves of the Barnacle Tree of Life that are only represented by taxonomy. Thus, our study demonstrates both the utility of the phylogenetic synthesis approach for obtaining a comprehensive understanding of the state of phylogenetic knowledge for a particular group, and the utility of taxonomy to add geographic information to dark parts of the tree to identify areas for future collecting efforts to complement existing phylogenetic information. Ultimately, this phylogeny serves as the first step to building a comprehensive Barnacle Tree of Life, so hypotheses regarding molecular and morphological barnacle evolution can be further tested.

\section{Materials \& Methods}

\section{Synthesis Approach}

The two key components in a synthesis phylogeny are first a comprehensive taxonomy of the group in question and second a set of phylogenetic estimates to be integrated with that taxonomy. First, we curated published barnacle phylogenies in the Open Tree of Life online curator (https://tree.opentreeoflife.org/curator) and mapped phylogeny terminals to the underlying taxonomy. We used the Open Tree taxonomy (OTT) ott2.9 (Rees and Cranston, 2017). The OTT is mainly based on the NCBI Taxonomy from the US National Center on Biotechnology Information (http://www.ncbi.nlm.nih.gov) reference taxonomy, but this taxonomy only includes taxa for which there are molecular data in GenBank. Therefore, to get as complete a taxonomic representation as possible, the NCBI taxonomy has been supplemented with the Backbone Taxonomy from the Global Biodiversity Information facility (www.gbif.org), the World Registry of Marine Species (WoRMS) (www.marinespecies.org) taxonomy, and the Interim Register of Marine and Nonmarine Genera from CSIRO (http://www.cmar.csiro.au/). These taxonomies follow, for the most part, Martin and Davis (2001) for the higher-level classification of the Thecostraca. The backbone taxonomy includes old as well as misspelled species names. These names inflate the number of species (i.e., binomials). We identified these invalid species by matching the tips of the synthesis phylogeny against the well-curated taxonomy of WoRMS and then removed invalid species from the synthesis phylogeny. We did not remove species that could only be identified to the genus level, as these potentially represent valid undescribed species.

If published phylogenies were not available in the Open Tree of Life git-based phylesystem repository (McTavish et al., 2015), we surveyed other public repositories and literature for phylogenetic studies on barnacles. For all studies of interest, we searched supplemental material, TreeBase (www.treebase.org), DataDryad (www.datadryad.org) and FigShare (www.figshare.org) for files of phylogenetic trees in a re-usable text format (e.g., nexus, newick, phylip, etc.). Unfortunately, the systematics community on average does not treat phylogenetic estimates as digital information to be deposited in an electronic repository (Drew et al., 2013). Therefore, if re-usable tree files were not available, we contacted the authors. If the authors were not able to provide tree files, we manually reconstructed newick trees in Mesquite v.3.40 (Maddison and Maddison, 2018) based on the phylogenetic tree presented in the respective study. These trees do not have meaningful branch lengths. This is acceptable as input for synthesis tree reconstruction because branch length information is not used in the tree

Peer] reviewing PDF | (2018:12:33472:2:0:NEW 24 Jun 2019) 
177

178

179

180

181

182

183

184

185

186

187

188

189

190

191

192

193

194

195

196

197

198

199

200

201

202

203

204

205

206

207

208

209

210

211

212

213

214

215

216

217

218

219

220

221

222

synthesis process.

One requirement of phylogenetic synthesis is to rank input phylogenies with the phylogeny that will carry the most weight first and the phylogeny that will carry the least weight last. This means the phylogeny ranked first will have its bifurcations favored over all others ranked below it in the final synthesis phylogeny. Due to this weighting scheme, we ranked the barnacle taxonomy last because we wanted all molecular or morphological input trees ranked ahead of the taxonomy and not taxa or branches represented by molecular or morphological data were represented by taxonomy. For the synthesis tree construction, we ranked molecular and morphological studies by three criteria:

(1) Scope: studies with a narrow phylogenetic scope, e.g., focused on one or a few genera, were ranked higher than studies with a broad scope. The rationale is that studies focusing on lower taxonomic ranks have a better resolution at the shallow nodes, while broader studies that contain a diversity of higher taxonomic ranks typically add little phylogenetic information at shallow nodes. Giving studies with narrow scope a higher rank means that in case of a conflict, those studies take precedence over the lower-ranked trees.

(2) Number of markers: if studies aimed to reconstruct the same most recent common ancestor, e.g., five studies attempting to resolve relationships within the Thoracica (Table 1), we ranked studies with more molecular markers higher. Here we assume that including more markers leads to better phylogenetic reconstructions, depicting evolutionary relationships more realistically. They are less likely to reconstruct gene trees, and more likely to reconstruct the "true" species tree.

(3) Number of taxa: if rankings could not be resolved based on the previous two criteria, we ranked studies including more genera or more species higher. This practice follows the idea that missing taxa can hamper the reconstruction of accurate species relationships (Zwickl and Hillis, 2002).

In addition to requiring ranked barnacle studies, additional software and information is needed to generate a synthesis tree. The synthesis tree was generated using propinquity (https://github.com/OpenTreeOfLife/propinquity) (Redelings and Holder, 2017), which requires the following software: otcetera $\mathrm{v} 0.0 .01$ (https://github.com/OpenTreeOfLife/otcetera) and peyotl v0.1.4 (https://github.com/OpenTreeOfLife/otcetera). Taxa not represented in the published phylogenies are represented by taxonomy only in the synthesis tree, allowing for identification of conflict between these sources of information and identifying taxa for which phylogenetic information is totally lacking. In the case of conflict between phylogenies and backbone taxonomy, the synthesis tree reflects the phylogeny rankings, not the taxonomy. We used OTT v3.0 (/home/bredelings/Devel/OpenTree/ott-3.0) taxonomy, while setting the root taxon to ott580064. The root taxon corresponds to most recent common ancestor of the barnacles according to the taxonomy. Lastly, the ranked order of the barnacle studies (supplemental file), paths to software and taxonomy, and the root taxon were entered into the propinquity configuration file and executed using the commands make and make check.

\section{Geographic information}

For all thecostracan species, we searched for occurrence data using currently accepted taxonomic names as well as their synonyms. For synonyms, we followed WoRMS (Boxshall et al., 2016) and ITIS (Integrated Taxonomic Information System, www.itis.gov/). We extracted occurrence data from the Global Biodiversity Information Facility (GBIF: http://www.gbif.org/, consulted May 2016). 


\section{Results}

\section{Synthesis Phylogeny Estimation}

We identified a total of 36 phylogenetic studies on barnacle evolution. We excluded 9 studies for which a subsequent study investigated the same species with more markers and/or additional species (often subsequent studies from the same authors) for a final set of 27 studies (Table 1). For 16 studies, we received the tree files from the authors. Herrara et al. (2015) had deposited their tree file in DataDryad, Lin et al. (2015) in TreeBase, and Hayashi et al. (2013) provided their tree file as supplemental information. For the remaining eight studies, we reconstructed the tree manually in Mesquite based on published figures. All trees are available in the "barnacles tree collection" of the Open Tree of Life online curator (https://tree.opentreeoflife.org/curator/collections/kcranston/barnacles).

The initial synthesis tree of barnacles (Thecostraca) contained a total of 2,272 tip labels (terminals), of which 202 tip labels were invalid species names (e.g., synonyms or misspellings) that were removed from the synthesis tree. Of the remaining species, 1,872 were described species or subspecies, and 198 were undescribed or unidentified species for a total of 2,070 tree tips. This synthesis tree is available in the supplement of this publication. Phylogenetic information was available for 239 described species (11.5\% of all barnacle species). This information was not evenly distributed among barnacle orders (Fig. 2). The order Sessilia had the highest absolute coverage, with 127 of 883 species (14.4\%) being represented in phylogenetic studies. The small order Ibliformes had the highest relative coverage $(25 \%)$ with 2 out of 8 species (Fig. 2). The other two orders of Thoracica, the Lepadiformes (203 species) and Scalpelliformes (450 species), were represented in phylogenetic studies by 27 and 34 species, respectively. The two orders of Rhizocephala (311 species), the Akentrogonida (43 species) and Kentrogonida (268 species), were relatively well represented in phylogenetic studies with 10 and 19 species, respectively. The Acrothoracica (71 species) are overall species-poor; its orders Cryptophialida (21 species) and Lithoglyptida (50 species) were represented in phylogenetic studies with 2 and 11 species, respectively. The two orders of Ascothoracida (106 species), the Dendrogastrida (50 species) and Laurida (56 species), are also relatively small, and only 5 ascothoracidan species were used in phylogenetic studies to understand the position of Ascothoracida at large. The enigmatic Facetotecta and Tantulocarida were represented by 1 and 2 species, respectively.

A completely resolved (bifurcating) tree would have 2,135 nodes, but the synthesis tree has only 442 bifurcating nodes, indicating that $79.3 \%$ of all nodes are unresolved. This is also apparent in the visualization of the synthesis tree (Fig. 3), where most nodes are polytomous. The tree visualization with its annotations (including the later described node support values) can be reconstructed via the interactive Tree of Life website (https://itol.embl.de/) (Letunic and Bork, 2019). We provide the synthetic tree and text files containing the tree annotations as supplemental material. After creating an iTOL account and uploading the tree to the website, the annotation files can be dragged and dropped onto the tree image. Polytomies are caused by missing phylogenetic information and indicates that the node is supported by taxonomic information alone. Our source trees provide phylogenetic information for 220 internal nodes. Of the 220 nodes, 191 have more support than conflict, 18 have more conflict than support, and 11 have equal number of supporting and conflicting source phylogenies (Fig. 3). The most 
269 conflicted node is the most recent common ancestor (mrca) of a clade containing e.g.

270 Amphibalanus improvisus and Tetraclita japonica formosana, which contains 41 genera and 419

271 terminal taxa. A. improvisus and T. japonica formosana are taken as representatives of this clade,

272 but have not been used in phylogenetic reconstructions. For the node in question, there are 8

273 phylogenies in conflict and 4 phylogenies that support the relationships in Figure 3. The largest

274

275

276

277

278

279

280

281

282

283

284

285

286

287

288

289

290

291

292

293

294

295

296

297

298

299

300

301

302

303

304

305

306

307

308

309

310

311

312

313

314 number of source phylogenies supporting an internal node is 5 and there are 16 nodes in the synthesis tree with 5 source trees supporting a node.

Phylogenetic information on more than one species was lacking for 19 out of 56 families, so we were unable to assess the monophyly of those taxa (Table 2). Of 38 families with phylogenetic information, 18 were monophyletic. All orders but the small Ibliformes were polyphyletic. Polyphylies are also prevalent at the lower taxonomic ranks, such as the genus level. These polyphyletic genera caused a large number of thecostracan barnacle species to be placed basally with regard to their congeners. Those species were not included into phylogenetic studies, but some of their congeners were. Those congeners revealed that the genus or higher taxonomy in question were not monophyletic, thus making it impossible to place the remaining congeners solely based on taxonomy. The genera Trianguloscalpellum and Arcoscalpellum, for example, are polyphyletic, leading to an accumulation of species of those two genera at the base of the Scalpellidae (Fig. 3). This broken taxonomy can only be fixed by taxonomic revisions that are congruent with current phylogenetic results. Only monophyletic taxa allow the placement of all members of a genus (or higher taxonomy) into the same branch, as is the case for the genus Scalpellum.

\section{Geographic Analysis}

GIS occurrence information was available for 596 species (supplemental table). Of those, 111 species were represented in phylogenetic studies, many of which belonged to the most frequently geo-referenced species. Species with few geo-references, on the other hand, were less often represented in phylogenetic studies. Exceptions are represented in Table 3. Comparing the distribution of taxa with and without geographic information reveals that the coasts of the USA, Europe and Australia have the highest density of records, both of species with and without phylogenetic information (Fig. 4). The deep sea and Antarctica, on the other hand, have very few records. Europe has the highest number of geo-referenced species that have also been sampled for phylogenetic studies (Fig. 4A), while species not yet included into phylogenetic studies are found along all coasts (Fig. 4B).

\section{Discussion}

Barnacles were one of the first model systems used in evolutionary biology (Darwin, 1851a; Darwin, 1851b; Darwin, 1854; Darwin, 1855), and have remained important in evolutionary (Charnov, 1987; Høeg and Møller, 2006; Høeg et al., 2009; Kelly and Sanford, 2010; Yusa et al., 2012), developmental (Mouchel-Vielh et al., 1998; Høeg et al., 2015; unpublished data, C. Ewers-Saucedo and P. Pappalardo), and ecological studies (Dayton, 1971; Grosberg, 1982; Shinen and Navarrete, 2010; Lamb et al., 2014). All these fields can benefit from phylogenetic information to account for the non-independence of species, and to unveil macroevolutionary patterns (Høeg, 1995; Pérez-Losada et al., 2009; Glenner et al., 2010; Rees et al., 2014; Lin et al., 2015; unpublished data, C. Ewers-Saucedo and P. Pappalardo). In the present study, we curated the available phylogenetic and taxonomic information for barnacles and reconstructed a 
315

316

317

318

319

320

321

322

323

324

325

326

327

328

329

330

331

332

333

334

335

336

337

338

339

340

341

342

343

344

345

346

347

348

349

350

351

352

353

354

355

356

357

358

359

360

complete synthesis phylogeny.

Recent phylogenetic efforts have investigated all major groups in the thecostracan tree. Twenty of the 27 studies we included focused on the Thoracica, the acorn and stalked barnacles (Table 1). This is not surprising, as these predominantly free-living barnacles are omnipresent in marine habitats, ecologically important and economically-costly fouling organisms. Rhizocephala are also relatively well-represented in phylogenetic studies. These specialized parasites of crabs and other economically-important crustaceans provide interesting model systems for development and host manipulation (Kobayashi et al., 2018). Fewer studies have considered the placement of the enigmatic Facetotecta, of which only the larvae are known, the Ascothoracida, ectoparasites of cnidarians and echinoderms (Pérez-Losada et al., 2009), and the shell-boring Acrothoracica (Lin et al., 2016). The number of species in a taxon and its phylogenetic coverage appear to be linked - i.e., less well-studied taxa contain fewer species. We hypothesize that these taxa contain much cryptic diversity, which has remained hidden to date. This hypothesis is supported by the findings of the first comprehensive molecular phylogeny of Acrothoracica (Lin et al., 2016), which included 11 described species, and identified an additional 12 cryptic operational taxonomic units (OTU's). This suggests that species diversity in the Acrothoracica could be twice as high as current species numbers indicate.

An unexpected result of our study is that even in geographic regions with a long history of marine research, such as the coasts of Europe, the United States and Australia, not all barnacle species have been included in phylogenetic analyses, and some of the most common species are lacking phylogenetic information, e.g. Amphibalanus improvisus (see Table 3 for more examples). Less surprising is the fact that remote regions, such as the open ocean and the Arctic coast, are under-sampled for many taxa, both with regard to phylogenetic and geographic information. While it should be relatively easy to include all barnacle species from marine biology hotspots into future phylogenetic studies, the under-sampling issue requires larger effort. However, remote regions potentially contain much of the existing phylogenetic diversity (Newman and Ross 1971) and could provide novel insights into the evolution of barnacles.

Our comparison of phylogenetic and taxonomic hypotheses revealed that many families were polyphyletic. These polyphylies lead to the accumulation of species from polyphyletic taxa at the base of the barnacle tree: all species that belong to polyphyletic taxa but have not themselves been included into phylogenetic studies can only be placed at the next higher taxonomic rank. The most extreme case of this "broken taxonomy" are the genera Pseudoacasta, Zulloana, Hexacreusia, Eoatria, Multatria, Microporatria, Bryozobia, Poratria, and Membranobalanus. These genera are placed at the very base of the Thoracica, next to the "real" sister taxon to the remaining Thoracica, the Ibliformes. They are, by no means, basal genera of the Thoracica, and their placement is an artefact of the tree synthesis. All of these genera belong to the Archaeobalanidae, a taxon that is highly polyphyletic. This disparity between phylogeny and taxonomy is likely caused by the use of morphological character sets to define taxonomy versus molecular characters used to estimate phylogeny. Furthermore, many barnacle taxa are still defined based on symplesiomorphic similarity or their classification relies on characters highly prone to homoplasy (Pérez-Losada et al., 2014; Gale, 2018). While there has been a robust debate on the relative merits of molecular versus morphological characters for estimating phylogenies, molecular characters have been especially useful to solve barnacle systematics. Within a morphologically-diverse taxon such as the barnacles, morphological characters may not be homologous, which further complicates the use of morphological data (Gale, 2016).

Additionally, larval characters are the only morphological datasets that can be compared across

Peer] reviewing PDF | (2018:12:33472:2:0:NEW 24 Jun 2019) 
361 all thecostracan taxa, but compiling them is difficult and time consuming (Høeg et al., 2009). To

362 address the discrepancies between taxonomy and phylogenies, a thorough revision of the

363 barnacle taxonomy is in order. To improve taxonomic assessments in the absence of molecular

364 data, morphological synapomorphies that are congruent with molecular phylogenetic

365 reconstructions should be identified (e.g., Høeg et al., 2009; Lin et al., 2015; Gale, 2018 and

366 references therein). These characters may then be applied to taxa for which molecular data

367 cannot be obtained at present, especially rare species, and species from remote areas of the

368

369

370

371

372

373

374

375

376

377

378

379

380

381

382

383

384

385

386

387

388

389

390

391

392

393

394

395

396

397

398

399

400

401

402

403

404

405

406 world, such as the deep sea and arctic regions. Extending the molecular-based trees using morphology is also crucial for integrating fossil information, which in barnacles offers an extensive and well-preserved set of taxa and characters (e.g., Pérez-Losada et al., 2008; Rees et al., 2015; Gale, 2018). It is also promising to see that larval characters studied at the ultrastructural level almost always match closely with molecular phylogenies (e.g., Høeg and Kolbasov 2002; Glenner et al., 2010).

Although we now have a working rendition of the Barnacle Tree of Life, much work is needed to confirm relationships among higher taxa and lower ranks. For example, the Superorder relationships have been supported by molecular and morphological data, but the barnacle phylogeny would benefit from a phylogeny of higher taxa based on genomic data. While currently there are 58 thecostracan transcriptomes on NCBI SRA database (last accessed March 13, 2018), no phylogenomic phylogenetic estimate has been generated yet. The taxonomic coverage of the available transcriptomes primarily covers Orders within Thoracica (Sessilia and Pedunculata), while one transcriptome is available for the Superorder Rhizocephala (Order Kentrogonida). A phylogenomic estimate for the Thecostraca would require obtaining additional samples for representatives in the Superorder Acrothoracica, Ascothoracida, Facetotecta and Tantulocarida (whose taxonomic position is still questionable). It should further be noted that no barnacle genomes are available despite their relatively small genome sizes of 0.67 to $2.60 \mathrm{C}$-value (Gregory, 2018).

Lastly, we would like to highlight the benefits of making phylogenetic trees available for further systematic research. The OTOL project provides a user-friendly interface to upload trees and metadata to the OTOL workflow (https://tree.opentreeoflife.org/curator). As we have done here, uploaded trees can be combined into a larger phylogenetic framework. This can help answer taxonomic questions, guide future phylogenetic efforts and allow the inclusion of a large number of species into comparative studies. To date, comparative studies have often been limited by the availability of phylogenetic information. Lin et al. (2015), for example, reconstructed a phylogeny for 77 barnacle species with various sexual systems, and mapped the evolution of sexes onto this tree. C. Ewers-Saucedo and P. Pappalardo (unpublished data), on the other hand, utilized the Barnacle Tree of Life to map all available larval trait data onto the thoracican tree, which allowed the inclusion of 170 thoracican species and did not require the collection of additional phylogenetic information.

\section{Conclusions}

This study provides the first working Barnacle Tree of Life, based on the phylogenetic information of 27 studies and a comprehensive taxonomic backbone. This tree highlights large gaps in our knowledge of barnacle phylogenetics, both with regard to taxonomy as well as geographic sampling. Nonetheless, this tree is a first working hypothesis for all barnacle species and provides therefore a valuable resource for comparative studies. The iterative nature of the 
407 OTOL project allows - and is fueled by - the inclusion of future phylogenetic studies, which will

408

409

410

411

412

413

414

415

416

417

418

419

420

421

422

423

424

425

426

427

428

429

430

431

432

433

434

435

436

437

438

439

440

441

442

443

444

445

446

447

448

449

450

continuously expand and improve the Barnacle Tree of Life.

\section{Acknowledgements}

We thank the authors who supplied their phylogenetic trees with their publication in a usable, rather than only viewable format. We also thank those authors who replied to our requests, sent us their tree data, and allowed us to make it publicly available as part of the Open Tree of Life project.

\section{References}

Bininda-Emonds O. 2004. The evolution of supertrees. Trends in Ecology and Evolution 19:315322.

Brickner I, Simon-Blecher N, Achituv Y. 2010. Darwin's Pyrgoma (Cirripedia) Revisited: Revision of the Savignium Group, Molecular Analysis and Description of New Species. Journal of Crustacean Biology 30:266-291. DOI: 10.1651/09-3152.1.

Brown JW, Wang N, Smith SA. 2017. The development of scientific consensus: Analyzing conflict and concordance among avian phylogenies. Molecular Phylogenetics and Evolution 116:69-77.

Buckeridge J. 1996. Phylogeny and biogeography of the primitive Sessilia and a consideration of a Tethyan origin for the group. Crustacean Issues 10:255-267.

Chen Y-Y. 2012. Biodiversity and Host Specificity of Coral-Inhabiting Barnacles in Taiwan. D. phil. Thesis, Academia Sinica, Taiwan.

Chan BKK, Corbari L, Rodriguez Moreno PA, Tsang LM. 2017. Molecular phylogeny of the lower acorn barnacle families (Bathylasmatidae, Chionelasmatidae, Pachylasmatidae and Waikalasmatidae) (Cirripedia: Balanomorpha) with evidence for revisions in family classification. Zoological Journal of the Linnean Society 180:542-555. DOI: 10.1093/zoolinnean/zlw005.

Charnov EL. 1987. Sexuality and hermaphroditism in barnacles: A natural selection approach. In: Southward AJ ed. Barnacle biology, Crustacean issues 5. Rotterdam: A. A. Balkema, 89-103.

Ciccarelli FD, Doerks T, Von Mering C, Creevey CJ, Snel B, Bork P. 2006. Toward automatic reconstruction of a highly resolved tree of life. Science 311:1283-1287.

Darwin C. 1851a. A monograph on the sub-class Cirripedia, with figures of all the species. The Lepadidae, or, pedunculated cirripedes. London: Ray society. DOI: 10.5962/bhl.title. 2104.

Darwin CR. 1851b. A monograph of the fossil Lepadidae or, pedunculated cirripedes of Great Britain. London: Paleontological Society.

Darwin C. 1854. A monograph on the sub-class Cirripedia, with figures of all the species. The Balanidae, the Verrucidae, etc. London: Ray society. DOI: 10.5962/bhl.title.2104.

Darwin CR. 1855. A monograph of the fossil Balanidae and Verrucidae of Great Britain. London: Paleontological Society. 
451

452

453

454

455

456

457

458

459

460

461

462

463

464

465

466

467

468

469

470

471

472

473

474

475

476

477

478

479

480

481

482

483

484

485

486

487

488

489

490

491

492

493

494

495

Dayton PK. 1971. Competition, Disturbance, and Community Organization: The Provision and Subsequent Utilization of Space in a Rocky Intertidal Community. Ecological Monographs 41:351-389. DOI: 10.2307/1948498.

Drew BT, Gazis R, Cabezas P, Swithers KS, Deng J, Rodriguez R, Katz LA, Crandall KA, Hibbett DS, Soltis DE. 2013. Lost Branches on the Tree of Life. PLOS Biology 11:e1001636. DOI: 10.1371/journal.pbio.1001636.

Driskell A, Ane C, Burleigh J, McMahon M, O'meara B, Sanderson M. 2004. Prospects for building the tree of life from large sequence databases. Science 306:1172-1174.

Gale AS. 2016. Phylogeny of the deep-sea cirripede family Scalpellidae (Crustacea, Thoracica) based on shell capitular plate morphology. Zoological Journal of the Linnean Society 176:266-304. DOI: 10.1111/zoj.12321.

Gale A. 2018. Stalked barnacles (Cirripedia, Thoracica) from the Upper Jurassic (Tithonian) Kimmeridge Clay of Dorset, UK; palaeoecology and bearing on the evolution of living forms. Proceedings of the Geologists' Association. DOI: 10.1016/j.pgeola.2018.01.005.

Glenner H, Hebsgaard MB. 2006. Phylogeny and evolution of life history strategies of the Parasitic Barnacles (Crustacea, Cirripedia, Rhizocephala). Molecular Phylogenetics and Evolution 41:528-538. DOI: 10.1016/j.ympev.2006.06.004.

Glenner H, Hoeg JT, Stenderup J, Rybakov AV. 2010. The monophyletic origin of a remarkable sexual system in akentrogonid rhizocephalan parasites: a molecular and larval structural study. Experimental Parasitology 125:3-12. DOI: 10.1016/j.exppara.2009.09.019.

Gregory TR. 2018. Animal Genome Size Database. Available at http://www.genomesize.com

Grosberg RK. 1982. Intertidal Zonation of Barnacles: The Influence of Planktonic Zonation of Larvae on Vertical Distribution of Adults. Ecology 63:894-899. DOI: 10.2307/1937228.

Harris DJ, Maxson LS, Braithwaite LF, Crandall KA. 2000. Phylogeny of the Thoracican Barnacles Based on 18s rDNA Sequences. Journal of Crustacean Biology 20:393-398. DOI: $10.2307 / 1549353$.

Hinchliff CE, Smith SA, Allman JF, Burleigh JG, Chaudhary R, Coghill LM, Crandall KA, Deng J, Drew BT, Gazis R, Gude K, Hibbett DS, Katz LA, Laughinghouse IHD, McTavish E, Midford PE, Owen CL, Ree RH, Rees JA, Soltis D, Williams T, Cranston K. 2015. Synthesis of phylogeny and taxonomy into a comprehensive tree of life. Proceedings of the National Academy of Sciences 112:12764-12769.

Høeg JT. 1995. Sex and the single cirripede. In: Schram FR, Høeg JT eds. New Frontiers in Barnacle Evolution; Crustacean Issues 10. Rotterdam: A. A. Balkema, 195-206.

Høeg JT, Chan BKK, Semmler LH. 2015. "Crustacea": Cirripedia. In: Evolutionary Developmental Biology of Invertebrates. Ecdysozoa II: Crustacea. Wien, New York: Springer, 153-181.

Høeg JT, Kolbasov GA. 2002. Lattice organs in y-cyprids of the Facetotecta and their significance in the phylogeny of the Crustacea Thecostraca. Acta Zoologica 83:67-79. DOI: $10.1046 / j .0001-7272.2001 .00100 . x$.

Høeg JT, Møller OS. 2006. When similar beginnings lead to different ends: Constraints and diversity in cirripede larval development. Invertebrate Reproduction \& Development 49:125-142. DOI: $10.1080 / 07924259.2006 .9652204$.

Høeg JT, Pérez-Losada M, Glenner H, Kolbasov G, Crandall K. 2009. Evolution of morphology, ontogeny and life cycles within the Crustacea Thecostraca. Arthropod Systematics and Phylogeny 67:199-217.

Peer) reviewing PDF | (2018:12:33472:2:0:NEW 24 Jun 2019) 
496

497

498

499

500

501

502

503

504

505

506

507

508

509

510

511

512

513

514

515

516

517

518

519

520

521

522

523

524

525

526

527

528

529

530

531

532

533

534

535

536

537

538

539

540

541

Kelly MW, Sanford E. 2010. The evolution of mating systems in barnacles. Journal of Experimental Marine Biology and Ecology 392:37-45. DOI: 10.1016/j.jembe.2010.04.009.

Kobayashi M, Wong Y, Oguro-Okano M, Dreyer N, Hoeg J, Yoschida R, Okano R. 2018. Identification, characterization, and larval biology of a rhizocephalan barnacle, Sacculina yatsui Boschma, 1936, from northwestern Japan (Cirripedia: Sacculinidae). Journal of Crustacean Biology.

Korn OM. 1995. Naupliar evidence for cirripede taxonomy and phylogeny. In: Schram FR, Høeg JT eds. New Frontiers in Barnacle Evolution. Rotterdam: A. A. Balkema, 87-121.

Lamb EA, Leslie HM, Shinen JL. 2014. Both like it hot? Influence of temperature on two cooccurring intertidal barnacles in central Chile. Journal of Experimental Marine Biology and Ecology 453:54-61. DOI: 10.1016/j.jembe.2014.01.001.

Letunic I, Bork P. 2019. Interactive Tree Of Life (iTOL) v4: recent updates and new developments. Nucleic Acid Research. DOI: 10.1093/nar/gkz239.

Lin H-C, Høeg JT, Yusa Y, Chan BKK. 2015. The origins and evolution of dwarf males and habitat use in thoracican barnacles. Molecular Phylogenetics and Evolution 91:1-11. DOI: $10.1016 /$ j.ympev.2015.04.026.

Lin H-C, Kobasov GA, Chan BKK. 2016. Phylogenetic relationships of Darwin's “Mr. Arthrobalanus": The burrowing barnacles (Cirripedia: Acrothoracica). Molecular Phylogenetics and Evolution 100:292-302. DOI: 10.1016/j.ympev.2016.03.016.

Maddison WP, Maddison DR. 2018. Mesquite: A modular system for evolutionary analysis.

Mallatt J, Giribet G. 2006. Further use of nearly complete 28S and 18S rRNA genes to classify Ecdysozoa: 37 more arthropods and a kinorhynch. Molecular phylogenetics and evolution 40:772-794.

Martin JW, Davis GE. 2001. An updated classification of the recent Crustacea.

McMahon MM, Sanderson MJ. 2006. Phylogenetic supermatrix analysis of GenBank sequences from 2228 papilionoid legumes. Systematic Biology 55:818-836.

McTavish EJ, Hinchliff CE, Allman JF, Brown JW, Cranston KA, Holder MT, Rees JA, Smith SA. 2015. Phylesystem: A git-based data store for community-curated phylogenetic estimates. Bioinformatics 31:2794-2800.

Mokady O, Loya Y, Achituv Y, Geffen E, Graur D, Rozenblatt S, Brickner I. 1999. Speciation versus phenotypic plasticity in coral inhabiting barnacles: Darwin's observations in an ecological context. Journal of Molecular Evolution 49:367-75.

Mouchel-Vielh E, Rigolot C, Gibert J-M, Deutsch JS. 1998. Molecules and the Body Plan: The Hox Genes of Cirripedes (Crustacea). Molecular Phylogenetics and Evolution 9:382389. DOI: $10.1006 / \mathrm{mpev} .1998 .0498$.

Owen CL, Bracken-Grissom H, Stern D, Crandall KA. 2015. A synthetic phylogeny of freshwater crayfish: insights for conservation. Philosophical Transactions of the Royal Society B: Biological Sciences 370:20140009. DOI: 10.1098/rstb.2014.0009.

Pérez-Losada M, Harp M, Høeg JT, Achituv Y, Jones D, Watanabe H, Crandall KA. 2008. The tempo and mode of barnacle evolution. Molecular Phylogenetics and Evolution 46:328346. DOI: 10.1016/j.ympev.2007.10.004.

Pérez-Losada M, Høeg JT, Crandall KA. 2004. Unraveling the Evolutionary Radiation of the Thoracican Barnacles Using Molecular and Morphological Evidence: A Comparison of Several Divergence Time Estimation Approaches. Systematic Biology 53:244-264. DOI: $\underline{10.1080 / 10635150490423458 .}$ 
542 Perez-Losada M, Hoeg J, Crandall K. 2009. Remarkable convergent evolution in specialized

543

544

545

546

547

548

549

550

551

552

553

554

555

556

557

558

559

560

561

562

563

564

565

566

567

568

569

570

571

572

573

574

575

576

577

578

579

580

581

582

583

584

585

586 parasitic Thecostraca (Crustacea). BMC Biology 7:15.

Pérez-Losada M, Høeg JT, Crandall KA. 2012. Deep Phylogeny and Character Evolution in Thecostraca (Crustacea: Maxillopoda). Integrative and Comparative Biology 52:430 442. DOI: $10.1093 / \mathrm{icb} / \mathrm{ics} 051$.

Pérez-Losada M, Høeg JT, Crandall KA, Achituv Y. 2012. Molecular phylogeny and character evolution of the chthamaloid barnacles (Cirripedia: Thoracica). Molecular Phylogenetics and Evolution 65:329-334. DOI: 10.1016/j.ympev.2012.06.004.

Pérez-Losada M, Høeg JT, Kolbasov GA, Crandall KA. 2002. Reanalysis of the relationships among the Cirripedia and the Ascothoracida and the phylogenetic position of the Facetotecta (Maxillopoda: Thecostraca) using 18S rDNA sequences. Journal of Crustacean Biology 22:661-669. DOI: 10.1651/02780372(2002)022[0661:ROTRAT]2.0.CO;2.

Pérez-Losada M, Hoeg JT, Simon-Blecher N, Achituv Y, Jones D, Crandall KA. 2014. Molecular phylogeny, systematics and morphological evolution of the acorn barnacles (Thoracica: Sessilia: Balanomorpha). Molecular Phylogenetics and Evolution 81c:147158. DOI: 10.1016/j.ympev.2014.09.013.

Petrunina AS, Neretina TV, Mugue NS, Kolbasov GA. 2014. Tantulocarida versus Thecostraca: inside or outside? First attempts to resolve phylogenetic position of Tantulocarida using gene sequences. Journal of Zoological Systematics and Evolutionary Research 52:100108. DOI: $10.1111 /$ jzs.12045.

Redelings BD, Holder MT. 2017. A supertree pipeline for summarizing phylogenetic and taxonomic information for millions of species. PeerJ 5:e3058.

Rees JA, Cranston K. 2017. Automated assembly of a reference taxonomy for phylogenetic data synthesis. Biodiversity Data Journal 5: e12581.

Rees DJ, Noever C, Hoeg JT, Ommundsen A, Glenner H. 2014. On the origin of a novel parasitic-feeding mode within suspension-feeding barnacles. Current Biology 24:142934. DOI: $10.1016 /$ j.cub.2014.05.030.

Ruppert E, Fox R, Barnes R. 2003. Invertebrate zoology: A functional evolutionary approach. Florence, Kentucky: Cengage Learning.

Shemesh E, Huchon D, Simon-Blecher N, Achituv Y. 2009. The distribution and molecular diversity of the Eastern Atlantic and Mediterranean chthamalids (Crustacea, Cirripedia). Zoologica Scripta 38:365-378.

Shinen JL, Navarrete SA. 2010. Coexistence and intertidal zonation of chthamalid barnacles along central Chile: Interference competition or a lottery for space? Journal of Experimental Marine Biology and Ecology 392:176-187. DOI: 10.1016/j.jembe.2010.04.033.

Simon-Blecher N, Hosie AM, Guy-Haim T, Chan BKK, Achituv Y. 2016. Speciation, phenotypic plasticity, or ontogeny, the case of the genus Galkinius (Pyrgomatidae, Cirripedia, Crustacea). Zoological Journal of the Linnean Society 176:305-322. DOI: 10.1111/zoj.12314.

Simon-Blecher N, Huchon D, Achituv Y. 2007. Phylogeny of coral-inhabiting barnacles (Cirripedia; Thoracica; Pyrgomatidae) based on 12S, 16S and 18S rDNA analysis. Molecular Phylogenetics and Evolution 44:1333-41. DOI: 10.1016/j.ympev.2007.03.026. 
587 Smith SA, Brown JW, Hinchliff CE. 2013. Analyzing and Synthesizing Phylogenies Using Tree Alignment Graphs. PLoS Computational Biology 9:e1003223. DOI:

589

590 10.1371/journal.pcbi.1003223.

Tsang LM, Chu KH, Nozawa Y, Chan BK. 2014. Morphological and host specificity evolution in coral symbiont barnacles (Balanomorpha: Pyrgomatidae) inferred from a multi-locus phylogeny. Molecular Phylogenetics and Evolution 77:11-22. DOI: 10.1016/j.ympev.2014.03.002.

Yorisue T, Chan Benny K. K., Kado Ryusuke, Watanabe Hiromi, Inoue Koji, Kojima Shigeaki, Høeg Jens T. 2016. On the morphology of antennular sensory and attachment organs in cypris larvae of the deep-sea vent/seep barnacles, Ashinkailepas and Neoverruca. Journal of Morphology 277:594-602. DOI: 10.1002/jmor.20522.

Yusa Y, Yoshikawa M, Kitaura J, Kawane M, Ozaki Y, Yamato S, Høeg JT. 2012. Adaptive evolution of sexual systems in pedunculate barnacles. Proceedings of the Royal Society B: Biological Sciences 279:959-966.

Zwickl D, Hillis D. 2002. Increased taxon sampling greatly reduces phylogenetic error. Systematic Biology 51:588-598. 


\section{FIGURE CAPTIONS}

605

606

607

608

609

610

611

612

613

614

615

616

617

618

619

620

621

622

623

624

625
Figure 1. Morphological diversity of barnacles and their allies (Thecostraca) mapped onto the phylogenetic hypothesis presented by Pérez-Losada et al. (2009). The Ibliformes are highlighted as the most basal Thoracican order with several potentially plesiomorphic features. Photographs taken by Benny K.K. Chan.

Figure 2. Distribution of phylogenetic and geographic information available across the main thecostracan orders. Bars represent the number of species, with different shades of grey denoting the number of species for which phylogenetic, geographic or both information are available. The asterisk indicates that no orders are defined for the infraclass Facetotecta.

Figure 3. Synthesis phylogeny of all thecostracan species. Species with phylogenetic information have a black dot adjacent to their names. Higher thecostracan taxonomy is colored and labeled accordingly (matching the taxonomic units presented in Fig. 1). Branch support/conflict values are plotted onto the branches. The first number indicates the number of input trees that support the branch, and the second number indicates the number of trees that conflict with the tree synthesis.

Figure 4. Geographic occurrence of thecostracan species with (A) and without (B) phylogenetic information, based on publicly available geographic occurrence records (Global Biodiversity Information Facility, www.gbif.org). 


\section{Figure 1}

Morphological diversity of Thecostraca mapped onto the phylogenetic hypothesis presented by Pérez-Losada et al. (2009).

The Ibliformes are highlighted as the most basal Thoracican order with several potentially plesiomorphic features. Photographs taken by Benny K.K. Chan.

*Note: Auto Gamma Correction was used for the image. This only affects the reviewing manuscript. See original source image if needed for review.

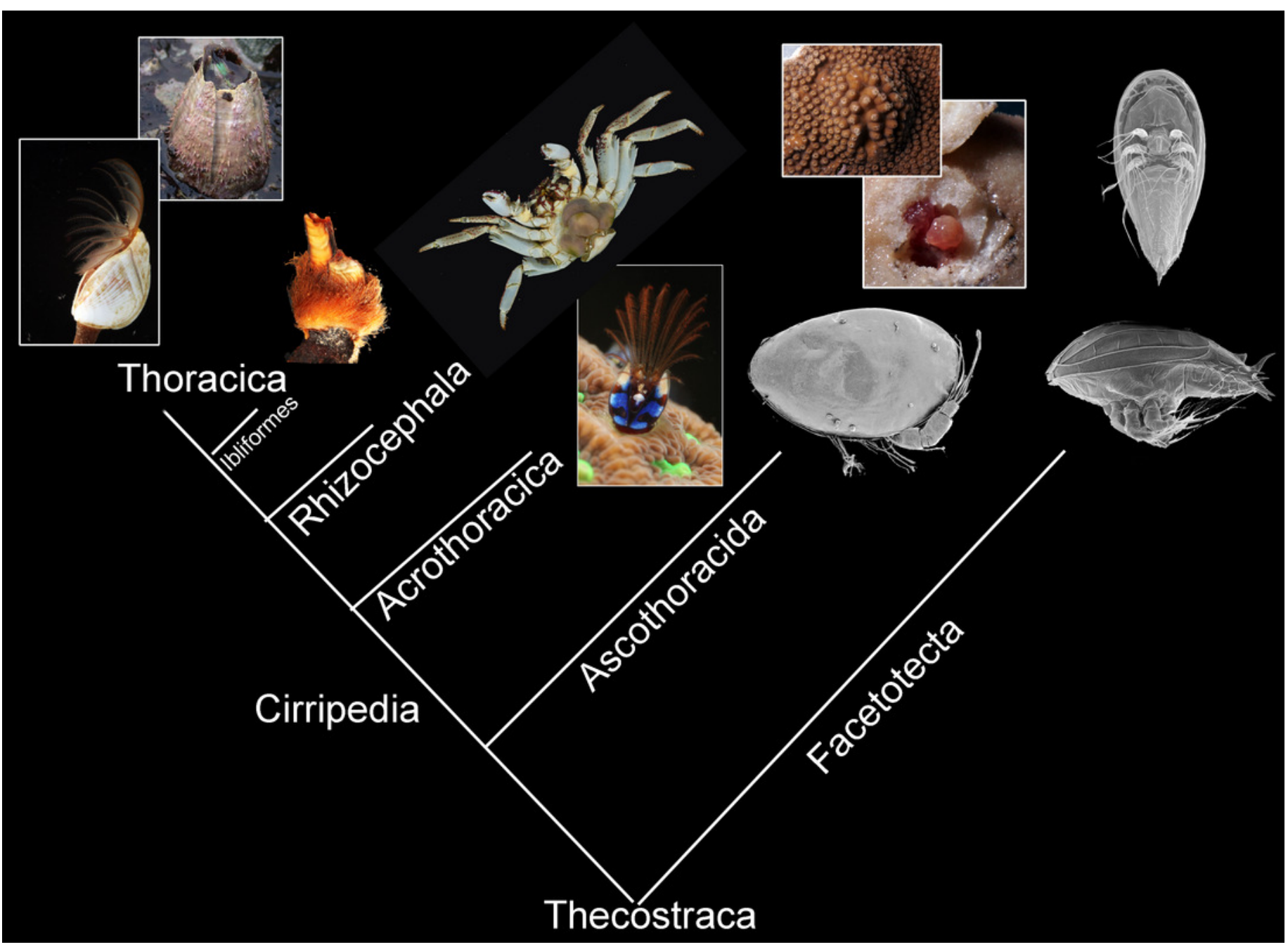


Figure 2 (on next page)

Distribution of phylogenetic and geographic information available across the main thecostracan orders.

Bars represent the number of species, with different shades of grey denoting the number of species for which phylogenetic, geographic or both information are available. The asterisk indicates that no orders are defined for the infraclass Facetotecta. 


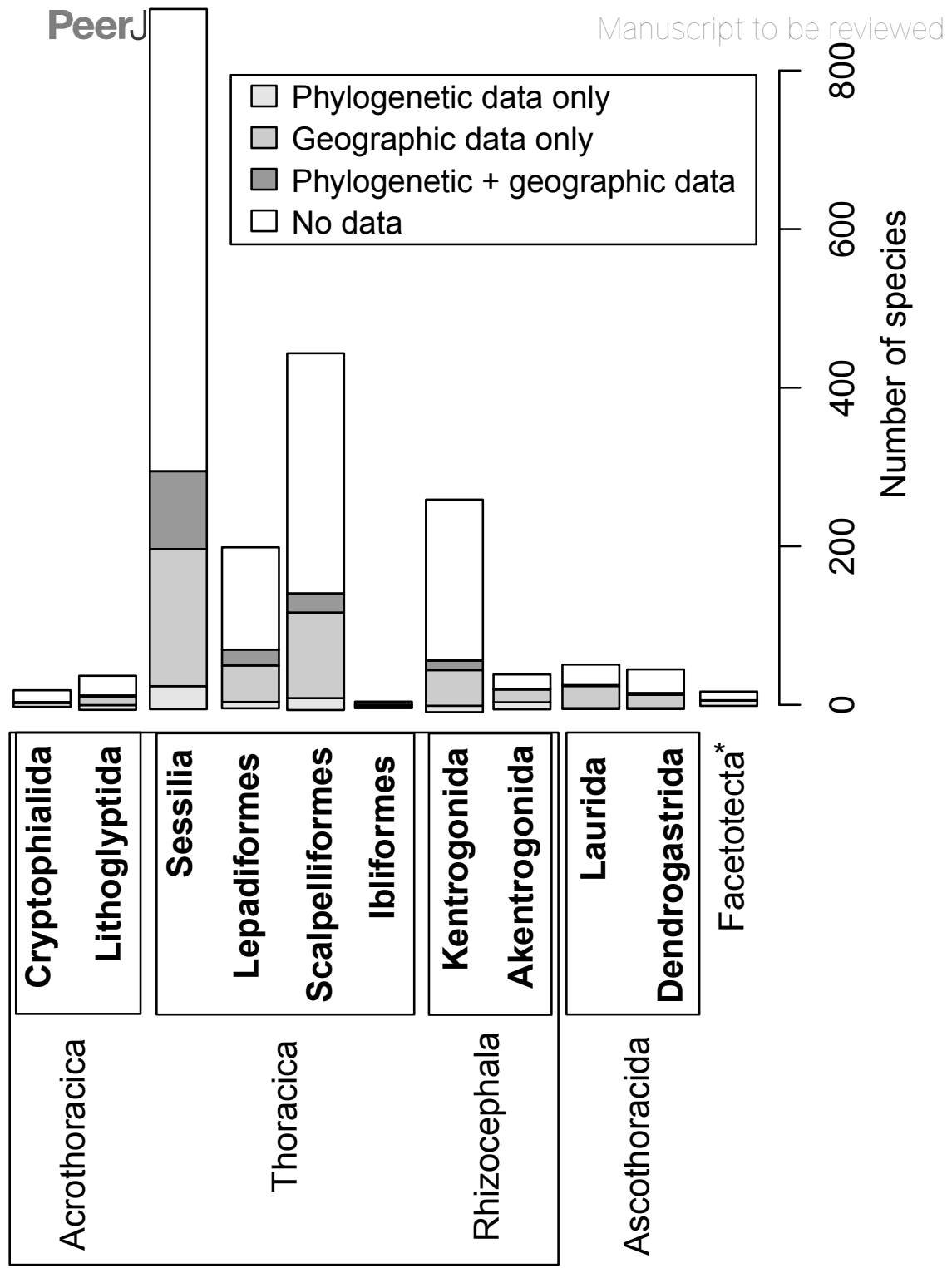

Peer) reviewing PQf (2018:12:33472:2:0:NEW 24 Jun 2019) 
Figure 3 (on next page)

Synthesis phylogeny of all thecostracan species.

Species with phylogenetic information have a black dot adjacent to their names. Higher thecostracan taxonomy is colored and labeled accordingly (matching the taxonomic units presented in Fig. 1). Branch support/conflict values are plotted onto the branches. The first number indicates the number of input trees that support the branch, and the second number indicates the number of trees that conflict with the tree synthesis. 


\section{Acrothoracica}

\section{Tantulocarida}

\section{Ascothoracida}

\section{Facetotecta}

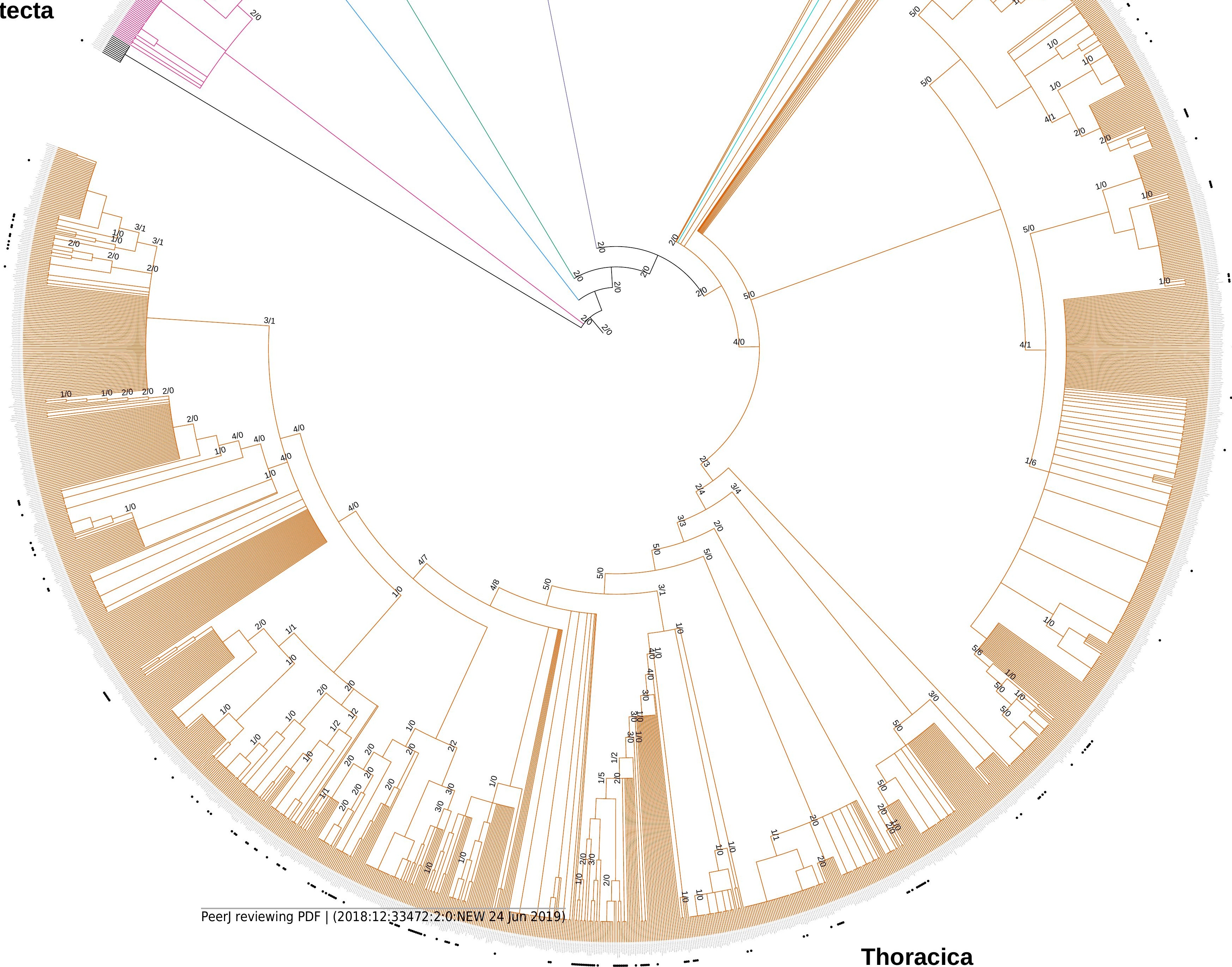


Figure 4 (on next page)

Geographic occurrence of thecostracan species with (A) and without (B) phylogenetic information, based on publicly available geographic occurrence records (Global Biodiversity Information Facility, www.gbif.org ). 
A PeerDistribution of species with phylogenetip informationed

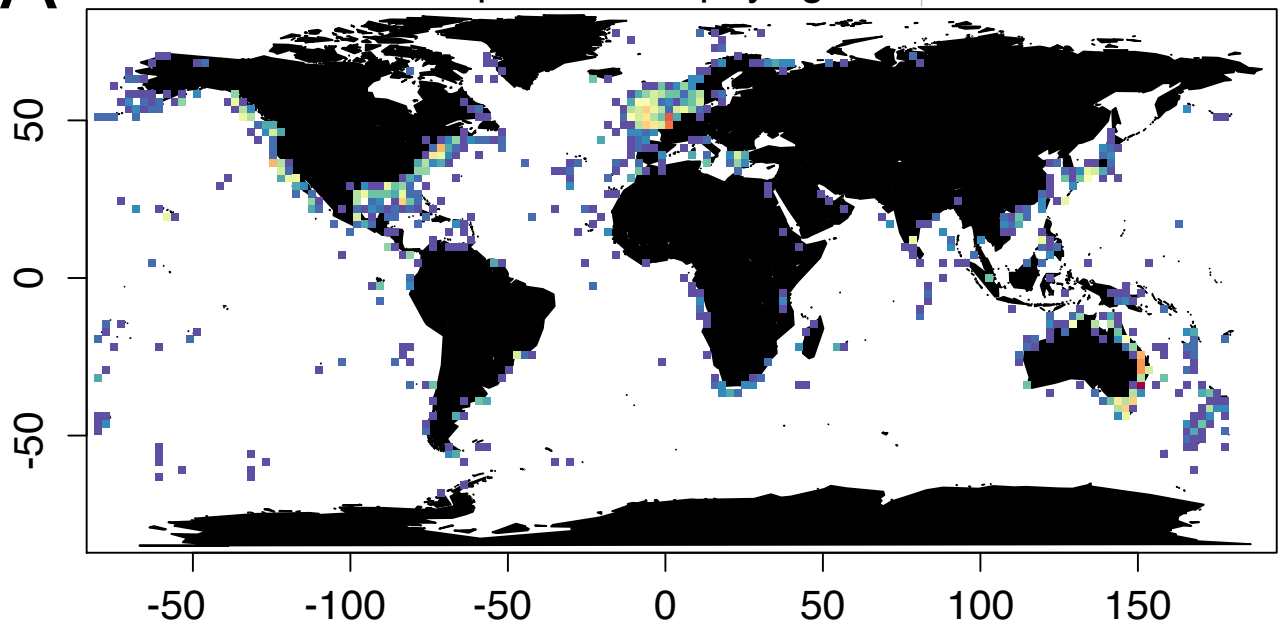

B Distribution of species without phylogenetic information

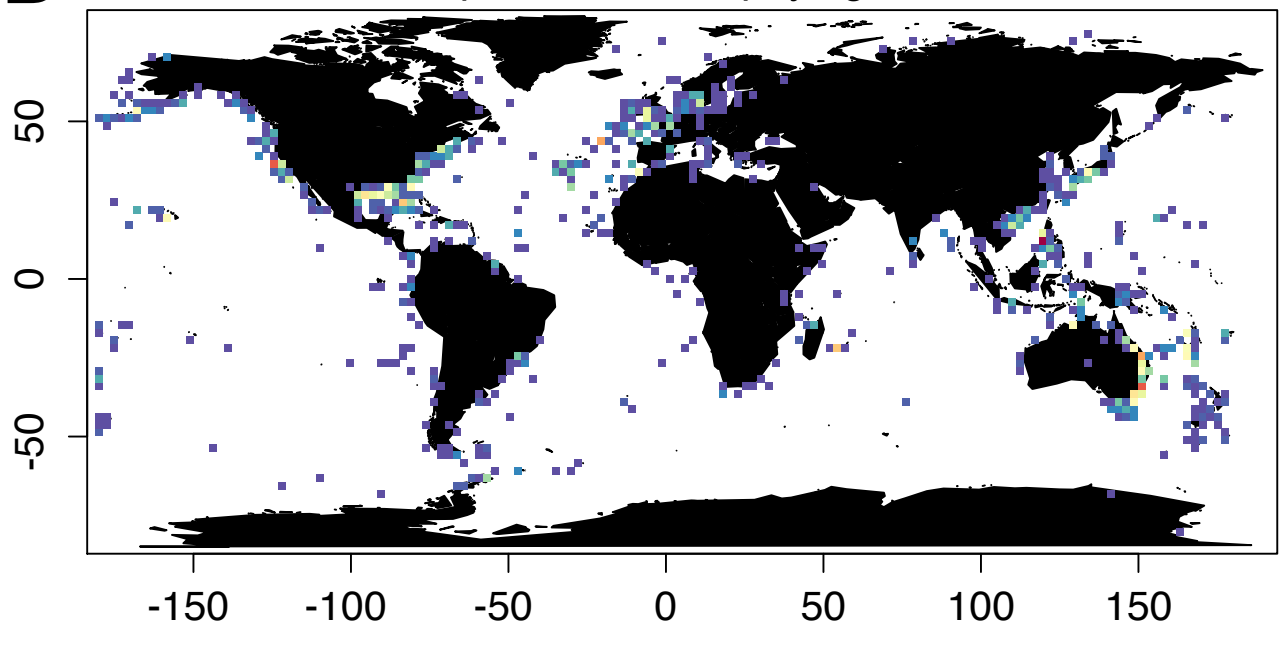

\# species

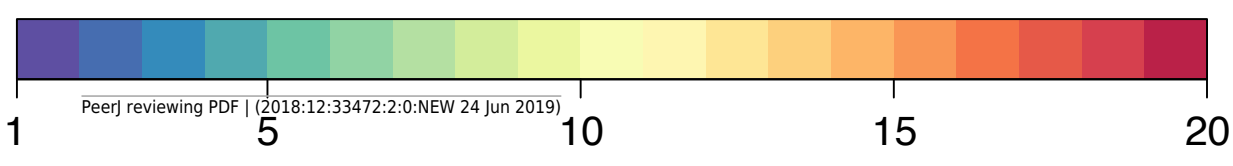




\section{Table $\mathbf{1}$ (on next page)}

Information on the phylogenetic studies used to synthesize the Barnacle Tree of Life.

Rank refers to the order in which a tree of the respective phylogenetic study was included into the synthesis approach. Focal taxon denotes the focal taxonomic unit of the publication. Scope refers to the taxonomic rank of the focal taxon. Markers are the markers used to reconstruct the phylogeny. Morphology refers to any number of morphological characters. All other markers refer to molecular DNA sequences, which amplified a gene or RNA fragment of the mitochondrial or nuclear genome. The mitochondrial markers were either 165 rRNA, and cytochrome oxidase subunit 1 (COI). The nuclear markers were 12S rRNA, 18S rRNA, 28S rRNA, histone 3 gene (H3), Na-K-ATPase (NKA), eukaryotic elongation factor $1 \alpha(E F 1 \alpha)$, and RNA polymerase subunit II (RPII). In most cases, only a fragment of the RNA or gene was amplified. Tree inference methods: BI: Bayesian inference, ML: maximum likelihood, MP: maximum parsimony, NJ: neighbor-joining. 
Table 1. Information on the phylogenetic studies used to synthesize the Barnacle Tree of Life.

Rank refers to the order in which a tree of the respective phylogenetic study was included into the synthesis approach. Focal taxon denotes the focal taxonomic unit of the publication. Scope refers to the taxonomic rank of the focal taxon. Markers are the markers used to reconstruct the phylogeny. Morphology refers to any number of morphological characters. All other markers refer to molecular DNA sequences, which amplified a gene or RNA fragment of the mitochondrial or nuclear genome. The mitochondrial markers were either 16S rRNA, and cytochrome oxidase subunit 1 (COI). The nuclear markers were 12S rRNA, 18S rRNA, 28S rRNA, histone 3 gene (H3), Na-K-ATPase (NKA), eukaryotic elongation factor $1 \alpha$ (EF1 $\alpha$ ), and RNA polymerase subunit II (RPII). In most cases, only a fragment of the RNA or gene was amplified. Tree inference methods: BI: Bayesian inference, ML: maximum likelihood, MP:

maximum parsimony, $\mathrm{NJ}$ : neighbor-joining.

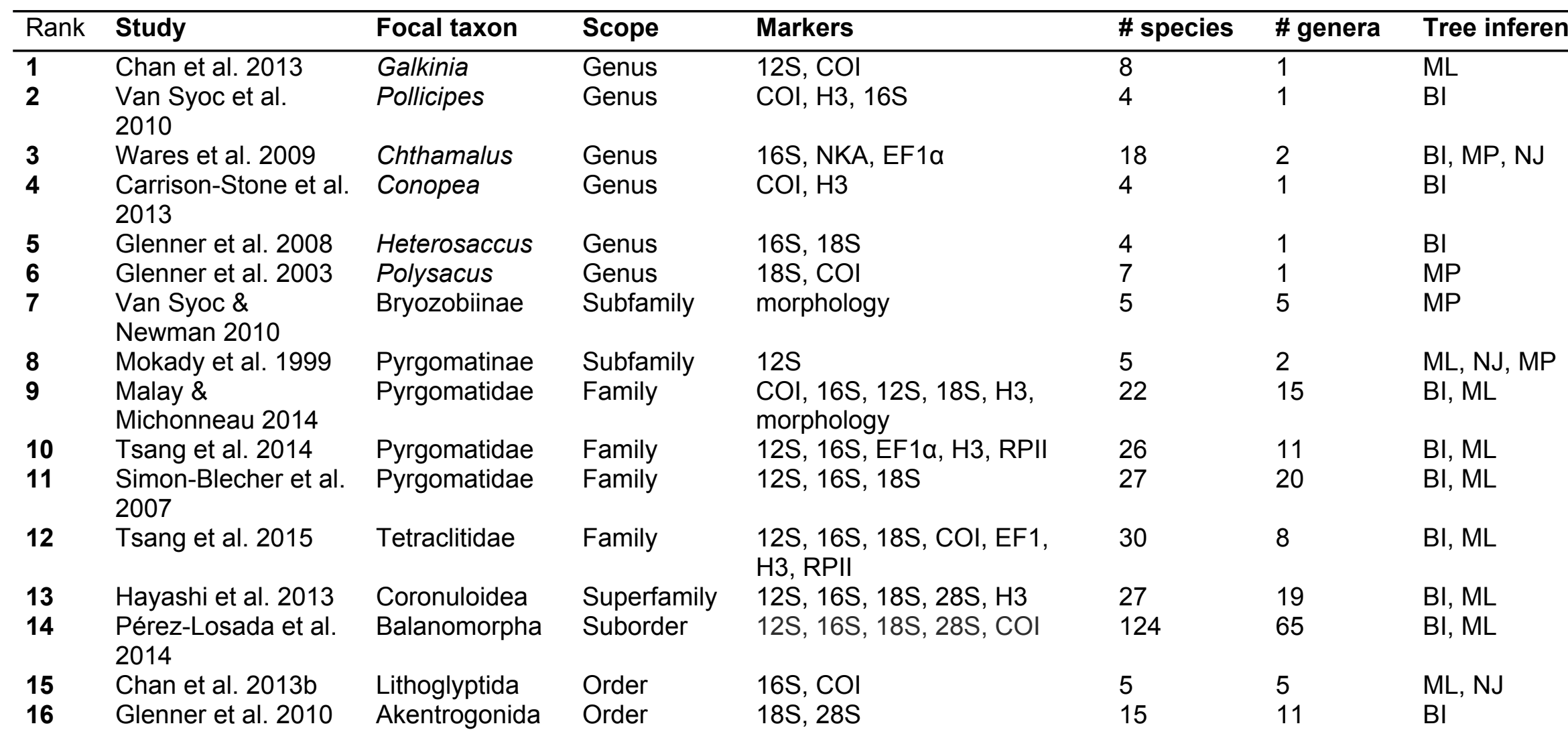




\begin{tabular}{|c|c|c|c|c|c|c|c|}
\hline 17 & Linse et al. 2013 & Scalpelliformes & Order & $18 \mathrm{~S}, 28 \mathrm{~S}, \mathrm{COI}$ & 10 & 6 & $\mathrm{BI}$ \\
\hline 18 & Lin et al. 2016 & Acrothoracica & Superorder & $16 \mathrm{~S}, 18 \mathrm{~S}, \mathrm{COI}, \mathrm{H} 3$ & 22 & 8 & $\mathrm{BI}$ \\
\hline 19 & Høeg et al. 2016 & Rhizocephala & Superorder & $16 S, 18 S, 28 S$ & 27 & 16 & $\mathrm{BI}, \mathrm{ML}$ \\
\hline 20 & $\begin{array}{l}\text { Glenner \& } \\
\text { Hebsgaard } 2006\end{array}$ & Rhizocephala & Superorder & $18 S$ & 22 & 16 & $\mathrm{BI}, \mathrm{ML}$ \\
\hline 21 & Lin et al. 2015 & Thoracica & Superorder & $12 \mathrm{~S}, 18 \mathrm{~S}, \mathrm{COI}, \mathrm{H} 3$ & 78 & 36 & $\mathrm{BI}$ \\
\hline 22 & Rees et al. 2014 & Thoracica & Superorder & $16 S, 18 S, 28 S$ & 98 & 59 & $\mathrm{BI}$ \\
\hline 23 & Herrera et al. 2015 & Thoracica & Superorder & 28S, COI, H3 & 100 & 52 & ML \\
\hline 24 & $\begin{array}{l}\text { Pérez-Losada et al. } \\
2008\end{array}$ & Thoracica & Superorder & $18 \mathrm{~S}, 28 \mathrm{~S}, \mathrm{H} 3$ & 76 & 43 & $\mathrm{BI}, \mathrm{ML}$ \\
\hline 25 & Yusa et al. 2012 & Thoracica & Superorder & $18 S$ & 48 & 27 & $\mathrm{BI}, \mathrm{ML}$ \\
\hline 26 & $\begin{array}{l}\text { Pérez-Losada et al. } \\
2009\end{array}$ & Thecostraca & Subclass & 18S, 28S, H3, morphology & 79 & 66 & $\mathrm{BI}, \mathrm{ML}$ \\
\hline 27 & $\begin{array}{l}\text { Petrunina et al. } \\
2014\end{array}$ & Thecostraca & Subclass & $18 S$ & 8 & 8 & $\mathrm{BI}$ \\
\hline
\end{tabular}




\section{Table 2 (on next page)}

Number of species in each family and the number and proportion (in parentheses) of species for which phylogenetic data or geographic information is available. 
Table 2. Number of species in each family and the number and proportion (in parentheses) of species for which phylogenetic data or geographic information is available.

\begin{tabular}{|c|c|c|c|c|}
\hline Family & Higher taxa & Total number of species & Phylogenetic data & Geographic information \\
\hline Anelasmatidae & Thoracica & 1 & $1(1.00)$ & $1(1.00)$ \\
\hline Archaeobalanidae & Thoracica & 161 & $8(0.05)$ & $29(0.18)$ \\
\hline Ascothoracidae & Ascothoracida & 9 & $0(0.00)$ & $3(0.33)$ \\
\hline Austrobalanidae & Thoracica & 18 & $4(0.28)$ & $8(0.44)$ \\
\hline Balanidae & Thoracica & 202 & $14(0.10)$ & $82(0.41)$ \\
\hline Calanticidae & Thoracica & 61 & $7(0.15)$ & $22(0.36)$ \\
\hline Catophragmidae & Thoracica & 3 & $2(0.67)$ & $1(0.33)$ \\
\hline Chelonibiidae & Thoracica & 9 & $5(0.44)$ & $5(0.56)$ \\
\hline Chionelasmatidae & Thoracica & 3 & $0(0.00)$ & $1(0.33)$ \\
\hline Chthamalidae & Thoracica & 67 & $33(0.48)$ & $24(0.36)$ \\
\hline Chthamalophilidae & Rhizocephala & 4 & $2(0.75)$ & $3(0.75)$ \\
\hline Clistosaccidae & Rhizocephala & 2 & $1(0.50)$ & $2(1.0)$ \\
\hline Coronulidae & Thoracica & 13 & $2(0.31)$ & $4(0.31)$ \\
\hline Cryptophialidae & Acrothoracica & 21 & $1(0.10)$ & $6(0.29)$ \\
\hline Ctenosculidae & Ascothoracida & 3 & $0(0.00)$ & $3(1.00)$ \\
\hline Dendrogastridae & Ascothoracida & 38 & $3(0.08)$ & $12(0.32)$ \\
\hline Duplorbidae & Rhizocephala & 5 & $0(0.00)$ & $2(0.40)$ \\
\hline Eolepadidae & Thoracica & 53 & $5(0.08)$ & $3(0.06)$ \\
\hline Heteralepadidae & Thoracica & 57 & $5(0.09)$ & $13(0.23)$ \\
\hline Iblidae & Thoracica & 3 & $2(0.67)$ & $2(0.67)$ \\
\hline Idioiblidae & Thoracica & 5 & $0(0.00)$ & $2(0.40)$ \\
\hline Koleolepadidae & Thoracica & 4 & $1(0.25)$ & $1(0.25)$ \\
\hline Lauridae & Ascothoracida & 18 & $1(0.06)$ & $3(0.17)$ \\
\hline Lepadidae & Thoracica & 27 & $8(0.30)$ & $11(0.41)$ \\
\hline Lernaeodiscidae & Rhizocephala & 17 & $1(0.06)$ & $6(0.35)$ \\
\hline Lithoglyptidae & Acrothoracica & 33 & $9(0.03)$ & $13(0.39)$ \\
\hline
\end{tabular}




\begin{tabular}{lllll} 
Lithotryidae & Thoracica & 6 & $3(0.50)$ & $2(0.33)$ \\
Malacolepadidae & Thoracica & 1 & $0(0.00)$ & $0(0.00)$ \\
Microlepadidae & Thoracica & 3 & $0(0.00)$ & $0(0.00)$ \\
Mycetomorphidae & Rhizocephala & 2 & $1(0.00)$ & $1(0.50)$ \\
Neoverrucidae & Thoracica & 30 & $3(0.10)$ & $0(0.00)$ \\
Oxynaspididae & Thoracica & 29 & $2(0.07)$ & $4(0.14)$ \\
Pachylasmatidae & Thoracica & 52 & $3(0.06)$ & $8(0.15)$ \\
Parthenopeidae & Rhizocephala & 2 & $1(0.50)$ & $1(0.50)$ \\
Peltogastridae & Rhizocephala & 45 & $4(0.09)$ & $12(0.27)$ \\
Petrarcidae & Ascothoracida & 11 & $1(0.09)$ & $8(0.73)$ \\
Platylepadidae & Thoracica & 24 & $9(0.38)$ & $8(0.33)$ \\
Poecilasmatidae & Thoracica & 70 & $10(0.16)$ & $30(0.43)$ \\
Pollicipedidae & Thoracica & 7 & $3(0.43)$ & $4(0.57)$ \\
Polysaccidae & Rhizocephala & 2 & $1(0.50)$ & $0(0.00)$ \\
Pyrgomatidae & Thoracica & 119 & $21(0.13)$ & $17(0.14)$ \\
Rhizolepadidae & Thoracica & 2 & $0(0.00)$ & $0(0.00)$ \\
Sacculinidae & Rhizocephala & 196 & $13(0.07)$ & $34(0.17)$ \\
Scalpellidae & Thoracica & 310 & $16(0.07)$ & $89(0.29)$ \\
Synagogidae & Ascothoracida & 27 & $0(0.00)$ & $18(0.67)$ \\
Tetraclitidae & Thoracica & 50 & $19(0.26)$ & $24(0.48)$ \\
Thompsoniidae & Rhizocephala & 25 & $5(0.12)$ & $1(0.04)$ \\
Trypetesidae & Acrothoracica & 7 & $2(0.00)$ & $4(0.57)$ \\
Verrucidae & Thoracica & 81 & $7(0.10)$ & $36(0.44)$ \\
\hline & & & &
\end{tabular}




\section{Table 3(on next page)}

Species with more than 30 geographic occurrence records (downloaded from www.gbif.org) but without phylogenetic data. 
1 Table 3. Species with more than 30 geographic occurrence records (downloaded from 2 www.gbif.org) but without phylogenetic data.

\begin{tabular}{lr}
\hline Species & GBIF records \\
\hline Amphibalanus improvisus & 1035 \\
Arcoscalpellum michelottianum & 131 \\
Striatobalanus amaryllis & 119 \\
Balanus rostratus & 86 \\
Trypetesa spinulosa & 74 \\
Meroscalpellum bifurcatum & 72 \\
Octolasmis orthogonia & 69 \\
Tesseropora rosea & 66 \\
Pollicipes elegans & 63 \\
Capitulum mitella & 56 \\
Neoscalpellum debile & 53 \\
Austrobalanus imperator & 50 \\
Arcoscalpellum portoricanum & 47 \\
Trypetesa lateralis & 42 \\
Acasta spongites & 38 \\
Anguloscalpellum pedunculatum & 33 \\
Acasta cyathus & 32 \\
Balanus laevis & 32 \\
Chionelasmus darwini & 32 \\
Notomegabalanus algicola & 32 \\
Armatobalanus quadrivittatus & 31 \\
Peltogaster paguri & 31 \\
Striatobalanus tenuis & \\
& \\
& 32 \\
\hline
\end{tabular}

